ARTICLE

Received 7 Dec 2012 | Accepted 24 Jul 2013 | Published 27 Aug 2013

DOl: $10.1038 /$ ncomms3348

OPEN

\title{
Use of domesticated pigs by Mesolithic hunter-gatherers in northwestern Europe
}

\author{
Ben Krause-Kyora ${ }^{1}$, Cheryl Makarewicz ${ }^{2}$, Allowen Evin ${ }^{3,4}$, Linus Girdland Flink ${ }^{5,6,7}$, Keith Dobney ${ }^{3}$, \\ Greger Larson ${ }^{5}$, Sönke Hartz ${ }^{8}$, Stefan Schreiber ${ }^{1,9}$, Claus von Carnap-Bornheim ${ }^{2,8,10}$, \\ Nicole von Wurmb-Schwark ${ }^{11} \&$ Almut Nebel $^{1}$
}

Mesolithic populations throughout Europe used diverse resource exploitation strategies that focused heavily on collecting and hunting wild prey. Between 5500 and 4200 cal BC, agriculturalists migrated into northwestern Europe bringing a suite of Neolithic technologies including domesticated animals. Here we investigate to what extent Mesolithic Ertebølle communities in northern Germany had access to domestic pigs, possibly through contact with neighbouring Neolithic agricultural groups. We employ a multidisciplinary approach, applying sequencing of ancient mitochondrial and nuclear DNA (coat colour-coding gene $M C 1 R$ ) as well as traditional and geometric morphometric (molar size and shape) analyses in Sus specimens from 17 Neolithic and Ertebølle sites. Our data from 63 ancient pig specimens show that Ertebølle hunter-gatherers acquired domestic pigs of varying size and coat colour that had both Near Eastern and European mitochondrial DNA ancestry. Our results also reveal that domestic pigs were present in the region $\sim 500$ years earlier than previously demonstrated.

\footnotetext{
${ }^{1}$ Institute of Clinical Molecular Biology, Christian-Albrechts-University, 24105 Kiel, Germany. ${ }^{2}$ Institute of Pre- and Protohistoric Archaeology, ChristianAlbrechts-University, 24105 Kiel, Germany. ${ }^{3}$ Department of Archaeology, University of Aberdeen, Aberdeen AB24 3UF, Scotland, UK. ${ }^{4}$ MNHN-CNRS, UMR7209, 75005 Paris, France. ${ }^{5}$ Durham Evolution and Ancient DNA, Department of Archaeology, Durham University, DH1 3LE Durham, UK. ${ }^{6}$ School of Biological and Biomedical Sciences, Durham University, DH1 3LE Durham, UK. ${ }^{7}$ Department of Palaeontology, Natural History Museum, SW7 5BD London, UK. ${ }^{8}$ Archäologisches Landesmuseum, Stiftung Schleswig-Holsteinische Landesmuseen Schloss Gottorf, 24837 Schleswig, Germany. ${ }^{9}$ Clinic for Internal Medicine I, University Hospital Schleswig-Holstein, 24105 Kiel, Germany. ${ }^{10}$ Center for Baltic and Scandinavian Archaeology, Stiftung Schleswig-Holsteinische Landesmuseen Schloss Gottorf, 24837 Schleswig, Germany. ${ }^{11}$ Institute of Legal Medicine, Christian-Albrechts-University, 24105 Kiel, Germany.

Correspondence and requests for materials should be addressed to A.N. (email: a.nebel@mucosa.de).
} 
$\mathrm{T}$ he spread of domesticated plants and animals throughout Europe between 6000 and $4000 \mathrm{cal} \mathrm{BC}$ involved a complex social and economic interplay between indigenous Mesolithic hunter-gatherers and incoming Neolithic farmers. Although contacts between these two groups were a feature of the social landscape ${ }^{1-3}$, the conduits through which the exchange and transfer of particular technological, subsistence and social elements might have occurred, and the scale of interaction remain hotly debated. More specifically, evidence regarding the degree to which local hunter-gatherers acquired elements of the introduced Neolithic farming 'package', or took ideas from their Neolithic neighbours and independently developed certain aspects of subsistence technologies, are controversial ${ }^{4}$.

In northern Europe, a number of claims have been made regarding the possibility that some hunter-gatherers had access to domestic animals ${ }^{5,6}$. Of the dozen or so previous assertions made for the presence of domestic sheep, goat, cattle or pig in Mesolithic contexts from Denmark, northern Germany, Poland and the Netherlands, almost all fail scrutiny in terms of their postulated early dates or their identification as domestic animals $^{5,6}$ (Supplementary Table S1). Interestingly, the only convincing cases to date are both from Ireland, where domestic cattle bones were recovered from late Mesolithic deposits ( $\sim 4300$ cal BC) at Ferriter's Cove and the slightly younger site at Kilgreany Cave ${ }^{5,7}$. Although these remains have been interpreted as the likely importation of joints of meat rather than live cattle $^{8}$, they clearly indicate late Irish Mesolithic links with continental European farmers at a time when no other evidence for such a connection exists in the archaeological record for Britain ${ }^{9}$. There remains as yet, however, no convincing evidence in continental northern Europe that late Mesolithic huntergatherers had access to domestic animals other than $\operatorname{dogs}^{5}$.

In the archaeological record of northern Europe, a long period of coexistence (circa 5500-4200 cal BC) has been documented between late Mesolithic groups and fully agricultural early Neolithic communities ${ }^{1-3}$. Of particular relevance is the Ertebølle hunter-gatherer culture of southern Scandinavia and northern Germany. In the southern part of their distribution range, the Ertebølle existed in close geographic proximity to Neolithic agricultural communities, first to the Linienbandkeramik (LBK; 5700/5600-4900 cal BC) and later on to the post-LBK communities (Stichbandkeramik 4900-4500 cal BC and Rössen $4500-4200 \mathrm{cal} \mathrm{BC})^{3,10-13}$. Some sporadic communication between these cultures is suggested by the presence in Ertebølle settlements of Danubian type or amphibolite axes and pottery exhibiting decoration styles similar to those frequently portrayed on LBK and Stichbandkeramik ceramics,10-13. However, in this potential 'zone of interaction', the Ertebølle appear to have maintained their own hunter-gatherer lifeway, distinct from their agricultural neighbours, likely resisting LBK and post-LBK acculturation altogether, 3 ,10-14.

Although Ertebølle subsistence was heavily oriented towards the exploitation of marine resources, wild ungulates-especially pigs (Sus scrofa)-provided an important supplement to the $\operatorname{diet}^{15-17}$. Sus bones comprised on average $\sim 30 \%$ of Ertebølle game assemblages ${ }^{15-17}$. Traditional biometrical analyses of Ertebølle pig skeletal remains indicated that these animals were mainly largebodied, and therefore were probably wild boar ${ }^{4,15-17}$. Although a single small 'domestic' pig has been claimed from the site of GrubeRosenhof, its 'domestic' attribution has been called into question ${ }^{5}$, as the identification is based on a scapula column length measurement, a dimension that in pigs is subject to considerable growth during the life of the animal ${ }^{18}$. As a result, convincing evidence for domestic pigs has yet to be reported from Ertebølle sites before $\sim 4200 \mathrm{cal}$ $\mathrm{BC}^{3-6,15-17}$. In contrast, the contemporary Neolithic farming economy was characterized by intensive exploitation of domestic plants and animals such as sheep, goat, cattle and pigs ${ }^{4,19-21}$. Although early Neolithic (LBK) domestic sheep and goats clearly originated from the Near East-as no wild progenitors of these species existed in Europe $e^{21}$-it is possible that domestic cattle and pigs may have had a local origin because of the Pan-Eurasian distribution of wild aurochsen and boar.

Although genetic studies are revealing a detailed picture of cattle $e^{20-23}$ and pig ${ }^{24-26}$ exploitation by early Neolithic farmers, none have been directed towards exploring whether the Mesolithic Ertebølle hunter-gatherers of northern Germany acquired domestic animals (directly or indirectly) from their early or middle Neolithic neighbours to the south. To address this question, we applied ancient DNA (aDNA) analysis to Sus remains recovered from Ertebølle, LBK and post-LBK settlements in temporal association, including the site of Rosenhof where previous disputed claims for the presence of both domestic cattle and pigs have been made $3,5,6$. An 80-bp fragment of the maternally inherited mitochondrial control region (from which phylogeographic information about the origin of the sampled animals can be inferred ${ }^{26-28}$ ) was successfully analysed in 63 out of 144 bone and tooth samples. The haplotype information derived from this fragment permits separation of pigs of Near Eastern-and (in this case) certainly domesticated-ancestry from those of European origin.

In addition, variation in the $M C 1 R$ gene, associated with different coat colour patterns, was successfully sequenced for seven specimens. Spotted coat colour phenotypes are commonly seen in many modern domestic breeds ${ }^{29-33}$. A recent study determined that all known MC1R mutations in Eurasian wild boar are synonymous, suggesting that MCIR alleles leading to anything other than wild-type camouflage coat colour are quickly eliminated in the wild ${ }^{32}$. As a result, the $M C 1 R$ gene has been used as a marker of hybridization between wild and domestic $S_{u s}{ }^{33}$ and can be used as evidence for domestication in archaeological specimens. Furthermore, geometric morphometric (GMM) analyses were carried out on all corresponding specimens where molar teeth were present $(N=92)$, to use molar shape to assess their wild or domestic status ${ }^{34}$ and contrast the results with traditional biometrics ${ }^{35}$ and aDNA results.

The combination of a genetic and morphometric approach applied to the 63 pig remains shows that Ertebølle huntergatherers acquired domestic pigs of varying size and coat colour that had both Near Eastern and European mitochondrial DNA (mtDNA) ancestry. Our results reveal that the northern European Mesolithic Ertebølle hunter-gatherers did not only possess domestic pigs like those of their agricultural neighbours, but that these animals were present in the region $\sim 500$ years earlier than has been previously demonstrated.

\section{Results}

The mtDNA sequences from the specimens recovered from LBK and post-LBK $(N=37)$ and Ertebølle $(N=26)$ sites in Germany (Fig. 1, Table 1) clustered into four previously described clades (Fig. 2, Table 2, Supplementary Data 1) ${ }^{24,26}$ : the Near Eastern haplotypes Y1 $(17.5 \%, N=11)$ and Y2 $(1.6 \%, N=1)$ and the European branches A $(31.7 \%, N=20)$ and C $(49.2 \%, N=31$; Table 1, Supplementary Data 2). LBK, post-LBK and Ertebølle sites share similar compositions of Near Eastern and European Sus haplotypes (Fisher's test, $P=0.3$; Table 1, Supplementary Data 2) but Ertebølle Sus have significantly larger molars (the Kruskal-Wallis test, $P<0.05$; Fig. 3).

The presence of Near Eastern Sus haplotypes in the LBK confirms previous observations that domesticated pigs of Near Eastern ancestry were introduced to Europe during the Neolithic 
period $^{24,25}$. More surprising is the presence of three Ertebølle pigs from Grube-Rosenhof (specimens: E24, E44) and Poel (E69) from northern and northeastern Germany that possessed the Near Eastern haplotype Y1 (Table 3, Supplementary Data 1, 2). This result indicates the presence of animals with an 'exotic' domestic origin in a hunter-gatherer context (Fig. 1, Table 3). In addition, one of these specimens (E24) revealed a range of other domestic traits: (a) homozygous for the $M C 1 R \mathrm{E}^{\mathrm{p}}$ allele 501, showing that the animal possessed a 'black spotted' coat colour, a domestic phenotype (Table 3, Supplementary Data 3); (b) GMM analyses of the second lower molar revealed a 'domestic shape' classification; and (c) the lower third premolar was rotated (Fig. 4), a pathology observed more often in domestic than in wild

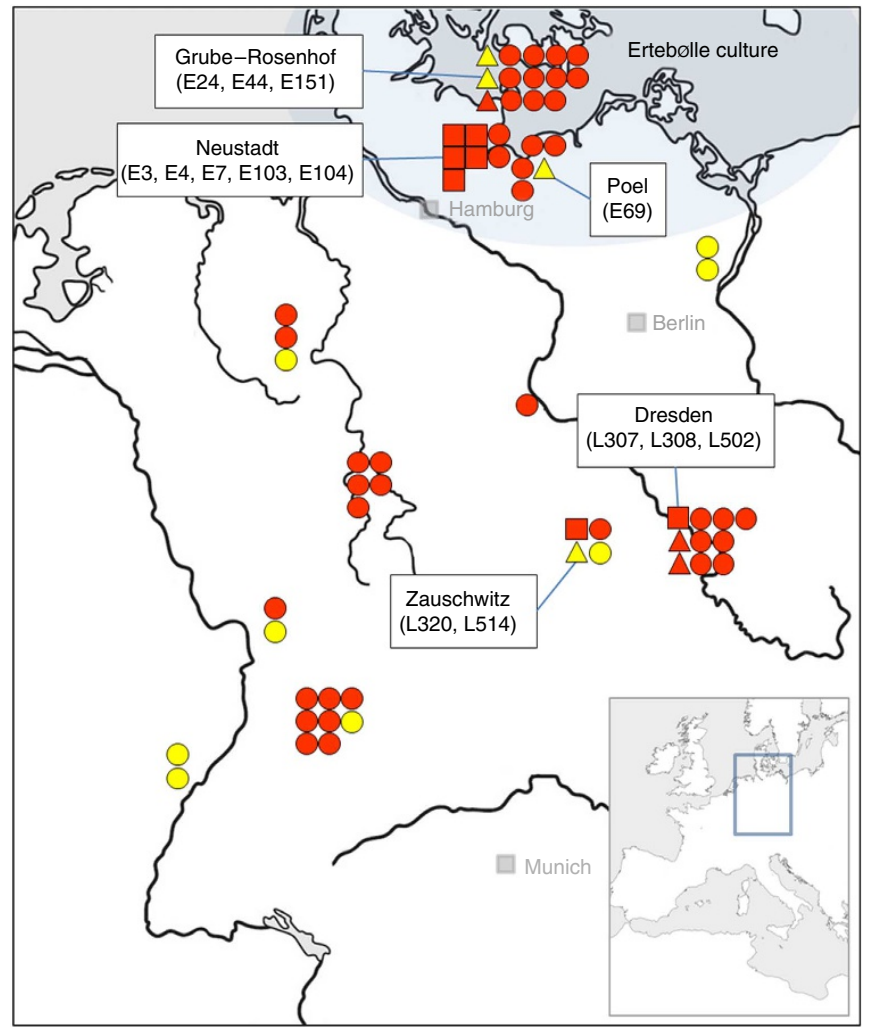

Figure 1 | Map depicting the location of the archaeological Sus samples from which mtDNA haplotypes were obtained. Samples were recovered from Neolithic LBK, post-LBK and Mesolithic Ertebølle sites dated between 5500 and $4000 \mathrm{cal} \mathrm{BC}$. Each symbol corresponds to a single sample (triangle, square and circle). Domestic (triangle) and wild (square) pigs discussed in the text are labelled; circles represent Sus specimens of unknown domestication status. The red colour indicates the European haplotypes $C$ and $A$, and yellow the Near Eastern haplotypes $Y 1$ and $Y 2$. animals $^{16,17}$. Finally, direct dating of E24 (4720-4582 cal BC, KIA 41338) confirmed its younger Ertebølle cultural affiliation $(\sim 4750-4450 \text { cal BC })^{3}$.

Although genetics, phenotype and pathology all strongly indicate that E24 represents the remains of a domestic animal, traditional biometry shows the specimen was very large (Fig. 3), falling within the modern-day size distribution of German wild boar and markedly outside that of modern European domestic pigs. A similarly large specimen (L320)-carrying the Near Eastern Y1 haplotype (Fig. 3, Table 3) and classified by GMM analyses as a 'domestic' pig shape-was identified at the Neolithic site of Zauschwitz in eastern Germany, further underscoring the unreliability of molar size as a definitive marker for domestic or wild status ${ }^{34}$

As Ertebølle and Neolithic groups (LBK, Stichbandkeramik and Rössen) coexisted for $\sim 700$ years (between 5500 and 4200 $\mathrm{cal} \mathrm{BC})^{1-3,12,13}$, the presence of a domestic pig dated from 4720 to $4582 \mathrm{cal} \mathrm{BC}$ at an Ertebølle site suggests that contact was frequent enough to be detected in the limited sample size analysed in this study. It seems that specimen E24 represents the earliest evidence of the first domesticated pigs introduced to the region.

By far the most frequent Sus mtDNA haplotypes in both LBK and post-LBK $(N=28)$ and Ertebølle $(N=23)$ sites are European haplogroups $A$ and $C^{26,28}$. As previous genetic evidence suggests that European wild boar were incorporated into domestic stocks soon after the introduction of Near Eastern pigs, individuals carrying European haplotypes could be either

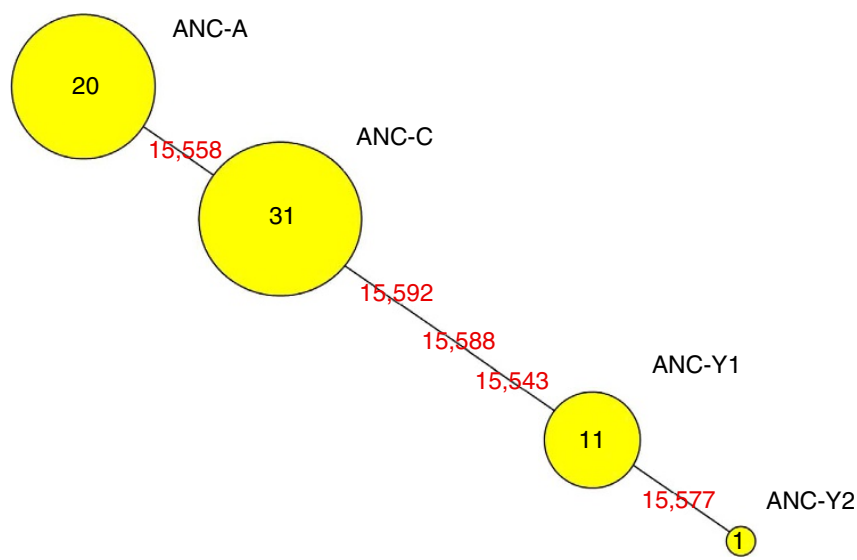

Figure 2 | The phylogenetic network based on haplogroups determined by the 80-bp-long diagnostic control region fragment of mtDNA. The phylogenetic network was constructed using the program Network ${ }^{45}$. The size of the circles is proportional to the number of individuals in each haplogroup-numbers are shown in the circles. Distances between the circles correspond to the number of mutations (positions indicated by red numbers) between the haplotypes.

Table 1 | Summary of mtDNA results of archaeological Sus samples.

\begin{tabular}{|c|c|c|c|c|c|c|c|}
\hline & \multirow[t]{2}{*}{ Sites (n) } & \multirow[t]{2}{*}{ Samples (n) } & \multirow{2}{*}{$\begin{array}{c}\text { Successfully } \\
\text { analysed samples }(n)^{\star}\end{array}$} & \multicolumn{4}{|c|}{ Haplotype $^{\dagger}$} \\
\hline & & & & European ANC-A & European ANC-C & Near East Y1 & Near East Y2 \\
\hline LBK and post-LBK & 12 & 106 & $37(35 \%)$ & 17 & 11 & 8 & 1 \\
\hline Ertebølle & 5 & 38 & $26(68 \%)$ & 3 & 20 & 3 & - \\
\hline Sum & 17 & 144 & $63(44 \%)$ & 20 & 31 & 11 & 1 \\
\hline
\end{tabular}


Table 2 | Variations of the 80-bp control region fragment of mtDNA used for phylogeographic analyses.

Mt genome position 15514-15593 (ref. 56): 5'-TAAAAATTGC GCACAAACAT ACAAATATGT GACCCCAAAA ATTTAACCAT TGAAAACCAA AAAATCTAAT ATACTATAAC-3'

\begin{tabular}{ll}
\hline Haplogroup & Sequence \\
\hline ANC-A & $5^{\prime}$-TAAAAATTGC GCACAAACAT ACAAATATGT GACCCCAAAA ATTTTACCAT TGAAAACCAA AAAATCTAAT ATACTATAAC-3' \\
ANC-C & $5^{\prime}$-TAAAAATTGC GCACAAACAT ACAAATATGT GACCCCAAAA ATTTAACCAT TGAAAACCAA AAAATCTAAT ATACTATAAC-3' \\
ANC-Y1 & $5^{\prime}$-TAAAAATTGC GCACAAACAT ACAAATATGC GACCCCAAAA ATTTAACCAT TGAAAACCAA AAAATCTAAT ATATTATAGC-3' \\
ANC-Y2 & $5^{\prime}$-TAAAAATTGC GCACAAACAT ACAAATATGC GACCCCAAAA ATTTAACCAT TGAAAACCAA AAA-TCTAAT ATATTATAGC-3' \\
\hline mtDNA, mitochondrial DNA. \\
The variants unique for the haplotypes are marked in bold in relation to the reference sequence ANC-C ${ }^{56}$. \\
\hline
\end{tabular}

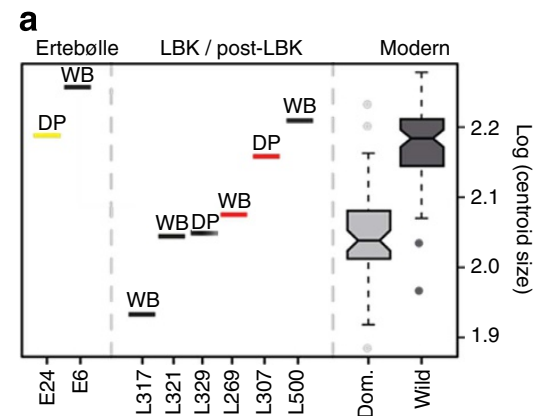

b

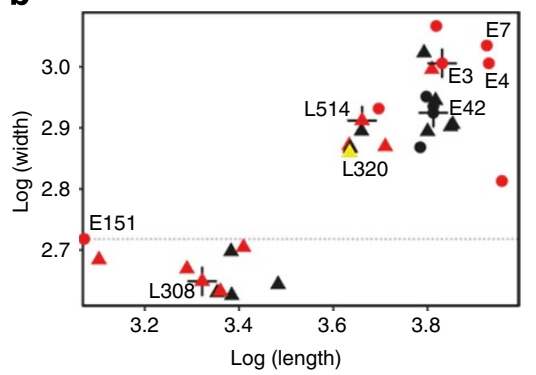

C

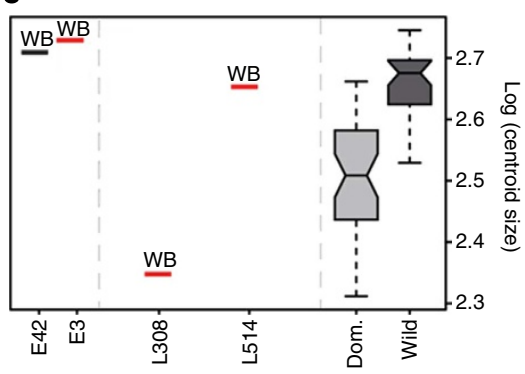

Figure 3 | Size variation of archaeological compared with modern Sus specimens. Ancient Sus samples compared with modern wild and domestic (Dom.) pigs for the lower second (a) and third (b,c) molars calculated using traditional metrics (b) and GMMs (a,c). Specimens analysed by both techniques are identified by a cross in $\mathbf{b}$. Where it was possible to identify specimens by their molar shape, they have been labelled as either domestic pig (DP) or wild boar (WB). Red indicates the European haplotypes $C$ and A, yellow the Near Eastern haplotypes Y1 and Y2. Black represents specimens for which no aDNA results were obtained.

wild or domestic animals. As a result, mtDNA sequences alone cannot be used to determine domestic or wild status in European suids. Using a combined genetic and morphometric approach, however, it was possible to more confidently assign status calls. For example, the combination of a European mtDNA haplotype, an $M C 1 R$ allele associated with wild coat colour and/or a wild tooth shape was interpreted as wild boar. Five Ertebølle (E3, E4, E7, E103 and E104) and two LBK/post-LBK (L502 and L514) specimens possessed this combination of criteria (Fig. 3, Table 3).

Although size can be a misleading indicator of domestication status $^{36}$, the presence of pigs smaller than modern wild boar that possessed European haplotypes found in both LBK and Ertebølle sites (Fig. 3, Table 3) was unexpected. One of these specimens (E151) from the Ertebølle site of Grube-Rosenhof in northern Germany also carried the $M C 1 R$ mutation associated with domestic coat colour. A small LBK specimen with a European mtDNA lineage (L308) from Dresden, Brodau in eastern Germany possessed a tooth shape more similar to wild boar than domestic pig. Another European LBK specimen (L307) from the same site represented a larger individual and possessed a domestic tooth shape. The wide disparities in molar size and shape present in these animals suggest that these traits provide a different signal of domestication for these European S. scrofa remains (Table 3).

A previous study concluded that European mtDNA haplotypes appeared in domestic swineherds around $4000 \mathrm{cal} \mathrm{BC}$, and then rapidly proliferated to become the dominant haplotype ${ }^{26,27}$. Although not directly dated, specimen E151-an animal of European mtDNA lineage exhibiting a domestic coat colourderives from a context dated by ${ }^{14} \mathrm{C}$ to between 4900 and $4400 \mathrm{cal}$ $\mathrm{BC}^{3}$, making it the earliest domesticated pig of European wild boar ancestry yet identified. These data suggest that the process of local domestication of European wild boar is perhaps 500 years earlier than previously recognized and was at least initiated by central European post-LBK cultures ${ }^{26}$. The fact that this first European domestic pig is in a Mesolithic context reveals evidence that Ertebølle hunter-gatherers had access to and acquired several kinds of domestic pig either directly or indirectly from their post-LBK neighbours (Stichbandkeramik and Rössen). 
Table 3 | Identification of wild boar and domestic pigs in Ertebølle and agricultural sites.

\begin{tabular}{|c|c|c|c|c|c|c|c|c|c|c|c|c|c|c|}
\hline & \multicolumn{7}{|c|}{ Wild boar } & \multicolumn{7}{|c|}{ Domestic pigs } \\
\hline & E3 & E4 & E7 & E103 & E104 & L502 & L514 & E24 $^{\star}$ & E44 $^{\star}$ & E69* & E151 $^{\star}$ & L307 & L308 & L320 \\
\hline mtDNA & EU & EU & EU & EU & EU & EU & EU & NE & $\mathrm{NE}$ & NE & EU & EU & EU & $\mathrm{NE}$ \\
\hline MCIR (allele) & $\begin{array}{c}\text { Wild } \\
(101 / 101)\end{array}$ & $\begin{array}{c}\text { Wild } \\
(101 / 101)\end{array}$ & $\begin{array}{c}\text { Wild } \\
(101 / 101)\end{array}$ & $\begin{array}{c}\text { Wild } \\
(101 / 101)\end{array}$ & $\begin{array}{c}\text { Wild } \\
(101 / 101)\end{array}$ & - & - & $\begin{array}{c}\text { Black spotted } \\
(501 / 501)\end{array}$ & - & - & $\begin{array}{c}\text { Black spotted } \\
(503 / 503)\end{array}$ & - & - & - \\
\hline $\begin{array}{l}\text { GMM (molar } \\
\text { shape) }\end{array}$ & WB & - & - & - & - & WB & WB & DP & - & - & - & DP & WB & - \\
\hline Molar size & Large & Large & Large & - & Large & Middle & Middle & Large & - & - & Small & Middle & Small & Middle \\
\hline
\end{tabular}

DP, domestic pig; EU, European haplotype (A and C); NE, Near Eastern haplotype (Y1); WB, wild boar.

'Wild' (wild type) and 'Black spotted' refer to the MCIR haplotypes. WB and DP refer to the identification based on molar shape analysis. 'Large', 'Middle' and 'Small' refer to the relative size of the specimens compared with the modern reference specimens. For GMM '- indicates no material is available; for MC1R ' - ' indicates no aDNA results are obtained. ${ }^{*}$ DPs found in Ertebølle contexts.

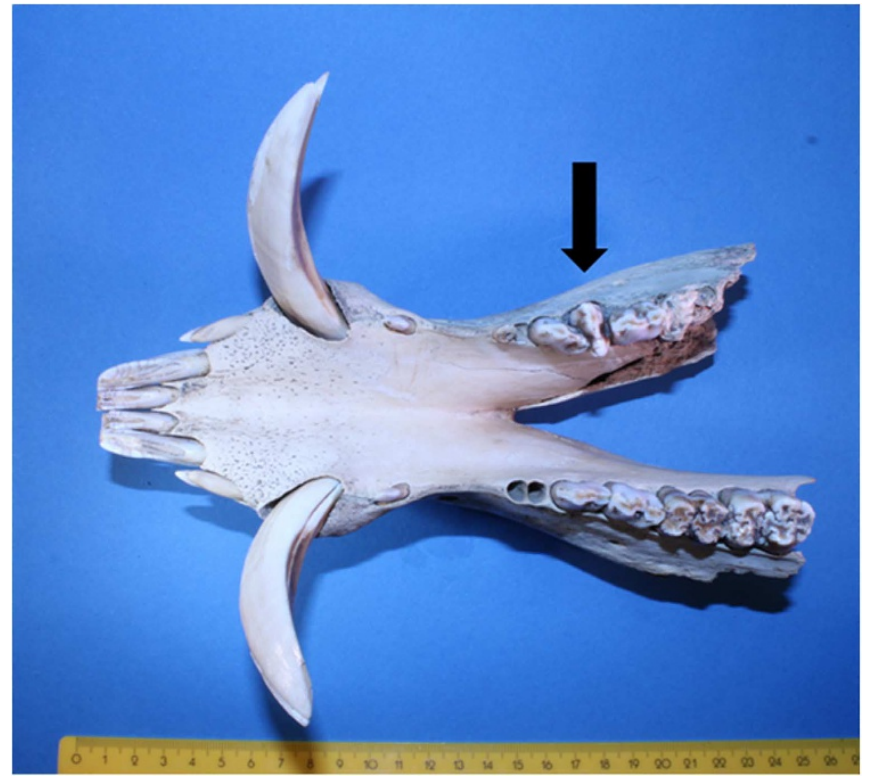

Figure 4 | Occlusal view of mandible. Specimen number E24. The rotated lower third premolar is indicated by an arrow. Measurement scale is in centimetres.

\section{Discussion}

Our results reveal a mixed and complex pattern of pig domestication, livestock management, breeding and cultural interaction between LBK and post-LBK farmers and huntergatherer communities in northern Europe. More or less contemporaneously, small and large (or relatively large compared with modern wild boar) domestic pigs of Near Eastern and European origin appeared in Ertebølle, LBK and post-LBK cultural contexts. Whether these pigs correspond to fully domesticated pigs, crosses between wild and domestic pigs, feral animals or pigs at the beginning of the domestication process remains unclear. A loose or more 'hands-off management strategy that encouraged domesticated pigs to forage unsupervised-a practice commonly used in non-intensive husbandry regimes today and in the past ${ }^{37}$-would have resulted in the escape of domestic pigs into the wild where they could have bred with wild boar. Near Eastern mtDNA haplotypes have so far not been observed in ancient or modern European wild boar ${ }^{26-28,30-33,38,39}$, suggesting that even if this did occur, the wild-domestic crosses have not left a significant mtDNA footprint in ancient or extant indigenous European wild boar populations.

The combination of a genetic and morphometric approach applied to the pig remains studied here demonstrates that the northern European Mesolithic Ertebølle hunter-gatherers possessed domestic pigs also kept by their agricultural (Stichbandkeramik and Rössen) neighbours. Whether these huntergatherer groups acquired domestic pigs via trade or exchange, or indirectly by hunting or capturing escaped animals remains unknown. What is clear, however, is that the acquisition of domestic pigs by these last hunter-gatherers was one (perhaps critical) component of a broader socioeconomic process by which the Ertebølle acquired and assimilated agricultural elements, eventually leading to the emergence of the Trichterbecher culture.

Although it is unclear why the Ertebølle sought domestic pigs, both large and small pigs with multi-coloured coats would likely have seemed strange and exotic compared with the more familiar appearance of the locally available wild boar they traditionally hunted. Whether mere subsistence or other factors led to the acquisition of domestic pigs, it did not immediately revolutionize hunter-gatherer animal exploitation strategies-the Ertebølle still hunted and gathered wild prey for hundreds of years while simultaneously exploiting a few domestic pigs. It did, however, ultimately open a gateway to lifeways centred on the continuous use of livestock as a dietary staple. Whether these two types of domestic pigs derive from the same mixed swineherd remains unknown; however, the genetic and morphometric data strongly suggest that early agriculturists employed a complex management and breeding strategy for suids. Rather than a simple developmental trajectory of exploitation from wild to domestic animals, our data suggest that both the domestication process and associated management scenarios were much more complex and involved than previously imagined.

What is clear is that these domestic pigs do, however, represent not only the first domestic animals identified from Mesolithic sites in continental northern Europe, but also the earliest domesticates from the region-appearing some 500 years before the first reliable evidence for domestic cattle, sheep or goat ${ }^{3-6,16,20,24,25}$.

\section{Methods}

aDNA quality control procedures. Preparation (that is, cutting, surface

decontamination and grinding) of bones and teeth, DNA extraction and pre-PCR processing were performed in three separate rooms dedicated to aDNA procedures, following established stringent protocols ${ }^{40-42}$. No modern DNA-based studies had ever been performed before in the rooms. All procedures were carried out in ultraviolet-irradiated DNA workstations. Access to the laboratory and handling of the archaeozoological material were limited to authorized personnel only. PostPCR work was routinely conducted in facilities different from those where aDNA was processed. Contamination prevention steps included the use of ultravioletirradiation, PCR workstations, disposable coveralls, masks and gloves ${ }^{40-42}$. Workbenches and surfaces were always bleached before experimental procedures. Only sterile RNA/DNA-free manufactured plasticware and filter tips in small packaging units were used. Disposable consumables and most of the solutions, buffers and $\mathrm{ddH}_{2} \mathrm{O}$ were irradiated with ultraviolet-light covered with aluminium foil $^{43}$. Negative controls were employed in all experimental steps (grinding, DNA extraction, pre-PCR preparation, PCR and sequencing) to rule out recent contamination. Primers applied in this study were specific for the genus Sus and showed no amplification success with DNA from humans or other animal species such as cattle, horse, cat or dog. A subset of four bone and tooth specimens 
was sent to the Ancient DNA Laboratory in Durham (UK), where for each case the mtDNA findings were verified (Supplementary Data 1,2).

Sample preparation and DNA extraction. Bones and teeth of 144 Sus specimens were investigated from 17 archaeological sites in Germany (Supplementary Data 1,2). The surface of all samples was sanded down with a circular saw and bleached to remove external contaminants. Samples were ground to fine-grained powder. DNA was extracted by a magnetic bead-based technology using the Biorobot-EZ1 (Qiagen, Hilden, Germany $)^{44}$. For each individual, a minimum of two independent DNA extractions were performed.

mtDNA sequence analysis. An 80 -bp-long diagnostic fragment from the control region of the Sus mitochondrial genome was amplified using two primer combinations (Supplementary Table S2). Amplicons ranged from 128 to $173 \mathrm{bp}$ in size and contained polymorphic sites that were used to define haplogroups and haplotypes. The amplification was carried out as singleplex PCR in a final volume of $25 \mu \mathrm{l}$ (Supplementary Table S3). The amplification was performed in a Mastercycler (Eppendorf, Hamburg, Germany) under the following conditions: initialization at $94^{\circ} \mathrm{C}$ for $11 \mathrm{~min} ; 35-42$ cycles at $94^{\circ} \mathrm{C}$ for $30 \mathrm{~s}, 52^{\circ} \mathrm{C}$ for $30 \mathrm{~s}, 72^{\circ} \mathrm{C}$ for $30 \mathrm{~s}$ and a final elongation step at $72^{\circ} \mathrm{C}$ for $10 \mathrm{~min}$. The amplification success was controlled by electrophoresis on a $2 \%$ agarose gel. Subsequently, $5 \mu$ l of the PCR products were treated with $2 \mu \mathrm{l}$ ExoSAP-IT (USB, Affymetrix, Freiburg, Germany) in a Mastercycler at $37^{\circ} \mathrm{C}$ for $15 \mathrm{~min}$ and at $80^{\circ} \mathrm{C}$ for $15 \mathrm{~min}$. The products were subjected to direct sequencing using the BigDye Terminator v3.1 Kit (Applied Biosystems, Foster City, USA). The sequencing conditions followed the instructions of the manufacturer. Sequencing products were purified applying the DyeEx 2.0 Spin Kit (Qiagen) and analysed using the ABI Prism 310 and 3130 Genetic Analyzers (Applied Biosystems). Sequences were aligned and verified manually with the programs DNA-Alignment ${ }^{45}$, DNAStar (Lasergen 8.0) and Bioedit (7.0.9). From each bone/tooth sample, a minimum of two extracts were prepared. For each extract that yielded amplifiable DNA, sequences were obtained independently at least twice. Only those samples that showed amplicons in more than one extract were considered for further analyses.

Coat colour analysis. Six fragments of the $M C 1 R$ gene were amplified to determine 14 nucleotide variations known to be associated with changes in coat colour in modern European pig breeds ${ }^{31}$ (Supplementary Table S4). The PCR primer sets are listed in Supplementary Table S5. The amplifications were carried out in singleplex PCRs in a final volume of $25 \mu \mathrm{l}$ (Supplementary Table S6). 7 deaza-2' -deoxyguanosine was used in the amplification to improve the processing of GC-rich regions ${ }^{46}$. The amplification was performed in a Mastercycler (Eppendorf) under the following conditions: initialization at $94^{\circ} \mathrm{C}$ for $11 \mathrm{~min} ; 15$ cycles at $94^{\circ} \mathrm{C}$ for $30 \mathrm{~s}, 60^{\circ} \mathrm{C}$ for $30 \mathrm{~s}+1{ }^{\circ} \mathrm{C}$ per cycle, $72^{\circ} \mathrm{C}$ for $30 \mathrm{~s} ; 25-27$ cycles at $94^{\circ} \mathrm{C}$ for $30 \mathrm{~s}, 60^{\circ} \mathrm{C}$ for $30 \mathrm{~s}, 72^{\circ} \mathrm{C}$ for $30 \mathrm{~s}$ and a final elongation step at $72^{\circ} \mathrm{C}$ for $10 \mathrm{~min}$. The amplification success was tested using gel electrophoresis followed by direct sequencing (see above).

To confirm the results, the $14 M C 1 R$ variants were also typed employing the single base extension (SBE) method using the SNaPshot Multiplex Kit (Applied Biosystems $)^{47}$. A multiplex PCR in a final volume of $25 \mu \mathrm{l}$ was performed under the same conditions as for the singleplex approach (Supplementary Table S6). The SBE reactions were carried out using the ABI Prism SNaPshot Multiplex reaction kit (Applied Biosystems) following the manufacturer's instructions. Two multiplex reactions were designed containing eight and six SBE primers, respectively (Supplementary Table S7), to increase the efficiency and sensitivity of the protocol for the analysis of highly degraded DNA. The components of the reaction mixes are reported in Supplementary Table S8. The cycling conditions are an initial step at $96^{\circ} \mathrm{C}$ for $6 \mathrm{~min}$, followed by 25 cycles of denaturation at $96^{\circ} \mathrm{C}$ for $10 \mathrm{~s}$, annealing at $55^{\circ} \mathrm{C}$ for $5 \mathrm{~s}$ and elongation at $60^{\circ} \mathrm{C}$ for $30 \mathrm{~s}$. Sequencing products were run on ABI Prism 310 and 3130 Genetic Analyzers (Applied Biosystems). The resultant electropherograms were analysed using GeneMapper version 3.2 Software (Applied Biosystems). Subsequently, the allelic status of the 14 loci was determined to infer the individual coat colour ${ }^{31}$

Verification of mtDNA results in Durham. DNA extraction was performed in the Ancient DNA Laboratory in the Archaeology Department at Durham University following strict laboratory procedures according to commonly applied guide-

lines ${ }^{40-42}$. All equipment and work surfaces were cleaned before and after each use with a dilute solution of bleach (10\%) followed by ethanol (99\%). A strict one-way system for entering the labs is in use to avoid introducing post-PCR contaminants.

The ancient pig remains were prepared for DNA extraction by removing a layer of the outer bone surface using a dremel drill with clean cut-off wheels (Dremel no. 409), targeting compact cortical bone. The bone was then pulverized in a microdismembrator (Sartorious-Stedim Biotech S.A., Aubagne Cedex, France). Bone powder was digested in $0.425 \mathrm{M}$ EDTA, $0.05 \%$ SDS, $0.05 \mathrm{M}$ Tris-HCI and $0.333 \mathrm{mg} \mathrm{ml}^{-1}$ proteinase $\mathrm{K}$, and was incubated overnight on a rotator at $50{ }^{\circ} \mathrm{C}$ until fully dissolved. The reagent master mix, excluding proteinase $\mathrm{K}$, was ultravioletirradiated at $254 \mathrm{~nm}$ for an hour using a crosslinker before suspension in extraction buffer. Two millilitres of supernatant was concentrated in a Millipore Amicon Ultra-4 $30 \mathrm{KDa}$ molecular weight cut-off to a final volume of $100 \mu \mathrm{l}$. The concentrated extract was purified using the QIAquick PCR Purification Kit (Qiagen) following the manufacturer's recommendations, with a final elution volume of $100 \mu \mathrm{l}$. One negative extraction control was performed alongside five to ten ancient bone samples.

PCRs for the mtDNA control region fragments were set up in $25-\mu l$ reactions (Supplementary Table S9). One PCR-negative control was included for every 5-8 aDNA template PCRs. PCR cycling conditions were $95^{\circ} \mathrm{C}$ for $5 \mathrm{~min}, 50$ cycles of $94^{\circ} \mathrm{C}$ for $45 \mathrm{~s}, 54^{\circ} \mathrm{C}$ for $45 \mathrm{~s}$ and $72^{\circ} \mathrm{C}$ for $45 \mathrm{~s}$, followed by $72^{\circ} \mathrm{C}$ for $10 \mathrm{~min}$. Sanger sequencing was performed on the Applied Biosystems 3730 DNA Analyser at the DNA Sequencing Service in the School of Biological and Biomedical Sciences at Durham University. Trace files were manually inspected with 4 Peaks (Mekentosj) or Geneious ${ }^{48}$ using the assembly function (default parameters).

GMM analyses. Maximum tooth length and width of molars were measured using a caliper $^{18,35}$. Differences in traditional molar size between pig specimens from Ertebølle and LBK sites were tested using Kruskal-Wallis tests. GMM techniques were used to analyse centroid size and shape of lower and upper second and third molars following a standardized protocol ${ }^{34,49}$. GMM data correspond to twodimensional landmark and sliding semi-landmark coordinates that were recorded and analysed ${ }^{34}$. GMM techniques were applied to available archaeological specimens that were identified as 'wild' or 'domestic' using predictive linear discriminant analyses. The modern reference specimens include 400 teeth corresponding to 73 modern German wild boar and 53 pigs from various European breeds ${ }^{34}$

(Supplementary Table S10). Archaeological specimens were labelled as 'middle' when showing a centroid size in the overlap of modern wild and domestic pig size, 'large' when above, and 'small' when below. Coordinates of landmarks and sliding semilandmarks were acquired with TpsDig2 v2.16 (ref. 50). TPS Relw v1.49 (ref. 51) was used to slide the semi-landmarks with the Procustes distance minimization criteria, and to superimpose all the specimens using a Generalized Procustes Analysis ${ }^{52,53}$. Predictive discriminant analyses were carried out using ' $R$ ' and 'Rmorph'54,55 to allocate the archaeological specimen to one of the two modern reference groups. Traditional size was visualized using biplots and centroid sizes using boxplots.

\section{References}

1. Andersen, S. H. The Mesolithic-Neolithic transition in western Denmark seen from a kitchen midden perspective: A survey. Between Foraging And Farming: An Extended Broad Spectrum Of Papers Presented To Leendert Louwe Kooijmans Analecta Praehistorica Leidensia 40, 67-74 (Leiden University Press, 2008).

2. Andersen, S. H. in First Pottery in Southern Scandinavia. Pots, Farmers and Foragers, Archaeological Studies Leiden University 20 (eds Vanmont, B., Kooijmans, L. L., Amkreutz, L. \& Verhart, L.) 167-176 (Leiden University Press, 2010).

3. Hartz, S., Lübke, H. \& Terberger, T. in Going over: The Mesolithic-Neolithic Transition in North-West Europe (eds Whittle, A. \& Cummings, V.) 567-594 (Oxford University Press, 2007).

4. Rowley-Conwy, P. How the west was lost. A reconsideration of agricultura origins in Britain, Ireland and southern Scandinavia. Curr. Anthropol. 45, 83-113 (2004).

5. Rowley-Conwy, P. in The Origins and Spread of Domestic Animals in Southwes Asia and Europe (eds Colledge, S., Conolly, J., Dobney, K., Manning, K. \& Shennan, S.) in press (Left Coast Press, 2013).

6. Rowley-Conwy, P. Westward ho! The spread of agriculturalism from central Europe to the Atlantic. Curr. Anthropol. 52, 431-451 (2011).

7. Woodman, P. \& McCarthy, M. in Neolithic Settlement in Ireland and Western Britain (eds Armit, I., Murphy, E., Nelis, E. \& Simpson, D.) 31-39 (Oxbow Book, 2003).

8. Tresset, A. in Neolithic Settlement in Ireland and Western Britain (eds Armit, I., Murphy, E., Nelis, E. \& Simpson, D.) 18-30 (Oxbow Book, 2003).

9. Sheridan, A. in Going over: the Mesolithic-Neolithic transition in north-west Europe. (eds Whittle, A. \& Cummings, V.) 441-492 (Oxford University Press, 2007).

10. Larsson, L. in Going over: The Mesolithic-Neolithic transition in North-West Europe (eds Whittle, A. \& Cummings, V.) 595-616 (Oxford University Press, 2007).

11. Klassen, L. Jade und Kupfer: Untersuchungen zum Neolithisierungsprozess im Westlichen Ostseeraum unter besonderer Berücksichtigung der Kulturentwicklung Europas 5500-3500 BC Vol. 47 (Jutland Archaeological Society Publications, 2004).

12. Dolukhanov, P. et al. The chronology of neolithic dispersal in Central and Eastern Europe. J. Archaeol. Sci. 32, 1441-1458 (2005).

13. Gronenborn, D. in Going over: The Mesolithic-Neolithic transition in North West Europe (eds Whittle, A. \& Cummings, V.) 73-98 (Oxford University Press, 2007).

14. Craig, O. E. et al. Ancient lipids reveal continuity in culinary practices across the transition to agriculture in Northern Europe. Proc. Natl Acad. Sci. USA 108, 17910-17915 (2011).

15. Rowley-Conwy, P., Albarella, U. \& Dobney, K. Distinguishing wild boar from domestic pigs in prehistory: a review of approaches and recent results. J. World Prehist. 25, 1-44 (2012). 
16. Magnell, O. Tracking Wild Boar and Hunters. Osteology of Wild Boar in Mesolithic South Scandinavia. In: Studies in Osteology I. Acta Archaeologica Lundensia Series. in $8^{\circ}$ No 51, 1-151 (Almqvist and Wiksell International, Stockholm, 2005).

17. Rowley-Conwy, P. \& Dobney, K. in Pigs and humans: 10,000 years of interactions (eds Albarella, U., Dobney, K., Ervynck, A. \& Rowley-Conwy, P.) 131-155 (Oxford Univ Press, 2007).

18. Payne, S. \& Bull, G. Components of variation in measurements of pig bones and teeth, and the use of measurements to distinguish wild from domestic pig remains. Archaeozoologia 2, 27-65 (1988).

19. Benecke, N. Archäologische Studien zur Entwicklung der Haustierhaltung in Mitteleuropa und Südskandinavien von den Anfängen bis zum ausgehenden Mittelalter. Schriften zur Ur- und Frühgeschichte 46 (Akad. Verl., 1994).

20. Tresset, A. \& Vigne, J. D. in Going over: The Mesolithic-Neolithic transition in North-West Europe (eds Whittle, A. \& Cummings, V.) 189-210 (Oxford University Press, 2007).

21. Zeder, M. A. Domestication and early agriculture in the Mediterranean basin: origins, diffusion, and impact. Proc. Natl Acad. Sci. USA 105, 11597-11604 (2008).

22. Scheu, A. et al. Ancient DNA provides no evidence for independent domestication of cattle in Mesolithic Rosenhof, northern Germany. J. Arch. Sci. 35, 1257-1264 (2008)

23. Edwards, C. J. et al. Mitochondrial DNA analysis shows a Near Eastern Neolithic origin for domestic cattle and no indication of domestication of European aurochs. Proc. Biol. Sci. 274, 1377-1385 (2007).

24. Bollongino, R. et al. Early history of European domestic cattle as revealed by ancient DNA. Biol. Lett. 2, 155-159 (2006).

25. Bollongino, R. et al. Modern taurine cattle descended from small number of Near-Eastern founders. Mol. Biol. Evol. 29, 2101-2104 (2012).

26. Larson, G. et al. Ancient DNA, pig domestication, and the spread of the Neolithic into Europe. Proc. Natl Acad. Sci. USA 104, 15276-15281 (2007).

27. Larson, G., Cucchi, T. \& Dobney, K. in The Genetics of the Pig (eds Rothschild, M. F. \& Ruvinsky, A.) 14-37 (CAB International, 2011).

28. Larson, G. et al. Worldwide phylogeography of wild boar reveals multiple centers of pig domestication. Science 307, 1618-1621 (2005).

29. Andersson, L. How selective sweeps in domestic animals provide new insights into biological mechanisms. J. Intern. Med. 271, 1-14 (2011).

30. Andersson, L. \& Plastow, G. in The genetics of the pig (eds Rothschild, M. F. \& Ruvinsky, A.) 38-50 (CAB International, 2011).

31. Fang, M. et al. Contrasting mode of evolution at a coat color locus in wild and domestic pigs. PLoS. Genet 5, e1000341 (2009).

32. Fajardo, V. et al. Differentiation of European wild boar (Sus scrofa scrofa) and domestic swine (Sus scrofa domestica) meats by PCR analysis targeting the mitochondrial D-loop and the nuclear melanocortin receptor $1(M C 1 R)$ genes. Meat Sci. 78, 314-322 (2008).

33. Koutsogiannouli, E. A. et al. Detection of hybrids between wild boars (Sus scrofa scrofa) and domestic pigs (Sus scrofa $f$ domestica) in Greece, using the PCR-RFLP method on melanocortin-1 receptor (MC1R) mutations. Mamm. Biol. 75, 69-73 (2010).

34. Evin, A. et al. The long and winding road: Identifying pig domestication through molar size and shape. J. Archaeol. Sci. 40, 735-743 (2013).

35. von den Driesch, A. E. A Guide to the Measurement of Animal Bones from Archaeological Sites Vol. 1 (Peabody Museum, 1976).

36. Zeder, M. A. et al. Documenting Domestication: New Genetic and Archaeological Paradigms (University of California Press, 2006).

37. Larson, G. et al. Phylogeny and ancient DNA of Sus provides insights into Neolithic expansion in Island Southeast Asia and Oceania. Proc. Natl Acad. Sci. USA 104, 4834-4839 (2007).

38. Kijas, J. M. \& Andersson, L. A phylogenetic study of the origin of the domestic pig estimated from the near complete mtDNA genome. J. Mol. Evol. 52, 302-308 (2001).

39. Scandura, M. et al. Ancient vs. recent processes as factors shaping the genetic variation of the European wild boar: are the effects of the last glaciation still detectable? Mol. Ecol. 17, 1745-1762 (2008)

40. Cooper, A. \& Poinar, H. N. Ancient DNA: do it right or not at all. Science 289, 1139 (2000).

41. Fulton, T. L. Setting up an ancient DNA laboratory. Methods Mol. Biol. 840, 1-11 (2012)

42. Champlot, S. et al. An efficient multistrategy DNA decontamination procedure of PCR reagents for hypersensitive PCR applications. PLoS One 5, e13042 (2010).

43. Tamariz, J. et al. The application of ultraviolet irradiation to exogenous sources of DNA in plasticware and water for the amplification of low copy number DNA. J. Forensic Sci. 51, 790-794 (2006).

44. Lee, E. J. et al. Emerging genetic patterns of the European Neolithic: perspectives from a late Neolithic Bell Beaker burial site in Germany. Am. J. Phys. Anthropol. 148, 571-579 (2012).
45. Bandelt, H. J., Forster, P. \& Röhl, A. Median-joining networks for inferring intraspecific phylogenies. Mol. Biol. Evol. 16, 37-48 (1999).

46. Frey, U. H. et al. PCR-amplification of GC-rich regions: 'slowdown PCR'. Nat. Protoc. 3, 1312-1317 (2008).

47. Haak, W. et al. Ancient DNA from European early Neolithic farmers reveals their Near Eastern affinities. PLoS Biol. 8, e1000536 (2010).

48. Drummond, A. J. et al. Geneious v5.4. Available from http://www.geneious.com/ (2011).

49. Cucchi, T. et al. Early Neolithic pig domestication at Jiahu, Henan Province, China: clues from molar shape analyses using geometric morphometric approaches. J. Archaeol. Sci. 38, 11-22 (2011).

50. Rohlf, F. J. tpsDig v2.16 Ecology and Evolution. http://life.bio.sunysb.edu/ morph/ (State University of New York at Stony Brook, 2010).

51. Rohlf, F. J. TPS Relative warps Ecology and Evolution. http://life.bio.sunysb.edu/ morph/(State University of New York at Stony Brook, 2010).

52. Rohlf, F. J. \& Slice, D. Extensions of the Procrustes method for the optimal superimposition of landmarks. Syst. Biol. 39, 40-59 (1990).

53. Goodall, C. R. in Current Issues In Statistical Shape Analysis. (eds Mardia, K. V. \& Gill, C. A.) 18-33 (University of Leeds Press, 1995).

54. R Development Core Team. $R$ : A Language and Environment for Statistical Computing.: R Foundation for Statistical Computing. http://www.r-project.org/ (R Development Core Team, 2011).

55. Baylac, M. Rmorph: a R geometric and multivariate morphometrics library (available from the author baylac@mnhn.fr) (2012).

56. Ursing, B. M. \& Arnason, U. The complete mitochondrial DNA sequence of the pig (Sus scrofa). J. Mol. Evol. 47, 302-306 (1998).

\section{Acknowledgements}

We thank the Archaeological State Museum Schleswig-Holstein, the Archaeological State Offices of Brandenburg, Lower Saxony and Saxony and the following individuals who provided sample material: Betty Arndt, Jörg Ewersen, Frederick Feulner, Susanne Hanik, Rüdiger Krause, Jochen Reinhard, Uwe Reuter, Karl-Heinz Röhrig, Maguerita Schäfer, Jörg Schibler, Reinhold Schoon, Regina Smolnik, Thomas Terberger and Ingrid Ulbricht. We are grateful to Ulrich Schmölcke, Michael Forster, Peter Forster and Aikaterini Glykou for their support and comments on the manuscript. We also thank many institutions and individuals that provided sample material and access to collections, especially the curators of the Museum für Naturkunde, Berlin; Muséum National $\mathrm{d}^{\prime}$ Histoire Naturelle, Paris; Smithsonian Institution, National Museum of Natural History, Washington D.C.; Zoologische Staatssammlung, München; Museum für Haustierkunde, Halle; the American Museum of Natural History, New-York. This work was funded by the Graduate School 'Human Development in Landscapes' at Kiel University (CAU) and supported by NERC project Grant NE/F003382/1. Radiocarbon dating was carried out at the Leibniz Laboratory, CAU.

\section{Author contributions}

B.K.-K., S.S., C.v.C.-B., N.v.W.-S. and A.N. conceived and designed the research. B.K.-K., L.G.F. and G.L. generated and analysed the ancient DNA data. A.E. and K.D. generated and analysed the GMM data. All authors contributed to analytical steps. S.H. provided contextual information and access to archaeological data. B.K.-K., C.M., A.E., K.D., G.L. and A.N. interpreted the findings and wrote the manuscript with input from L.G.F. and S.H.

\section{Additional information}

Accession codes: The obtained mitochondrial and nuclear sequences have been deposited in the NCBI GenBank nucleotide database under accession numbers KF274958KF275020 and KF418278-KF418312.

Supplementary Information accompanies this paper at http://www.nature.com/ naturecommunication

Competing financial interests: The authors declare no competing financial interests.

Reprints and permission information is available online at http://npg.nature.com/ reprintsandpermissions/

How to cite this article: Krause-Kyora, B. et al. Use of domesticated pigs by Mesolithic hunter-gatherers in northwestern Europe. Nat. Commun. 4:2348 doi: $10.1038 /$ ncomms3348 (2013).

This work is licensed under a Creative Commons AttributionNonCommercial-NoDerivs 3.0 Unported License. To view a copy of this license, visit http://creativecommons.org/licenses/by-nc-nd/3.0/ 